\title{
On Watson, Racism, and Standardized Tests
}

\author{
Joseph I. Shapiro, MD
}

Author affiliations are

listed at the end of this

article.

Correspondence to:

Joseph I. Shapiro, MD

Marshall University

Joan C. Edwards

School of Medicine

shapiroj@marshall.edu

\section{KEYWORDS}

Racism, Standardized Tests

The New York Times ran an article concerning the opinions voiced by Dr. James D. Watson, Nobel Laureate, and essentially the founder of modern molecular genetics. Dr. Watson alleged in 2007 that he was "inherently gloomy about the prospect of Africa" because "all our social policies are based on the fact that their intelligence is the same as ours whereas all the testing says not really." This outburst followed a number of other controversial comments by Dr. Watson which could easily be construed as racist (as well as some that were outrageously homophobic). In a recent interview, he stands by his earlier statements supporting a genetic basis for intelligence with significant differences among races. This stand has been at considerable cost; Dr. Watson has lost his titles and positions within the Cold Spring Harbor Laboratory and become (in his own terms) "a nonperson."1

First, it is worth reiterating the importance of Dr. Watson's groundbreaking work with DNA, which was published with Dr. Francis Crick in 1953 and for which he shared the Nobel Prize with Drs. Crick and Maurice Wilkins. This finding is arguably the most important biological finding of the 20th century. With the understanding that genes (in higher animals) were constituted by complementary strands of DNA, the world of modern molecular genetics was ushered in. ${ }^{2}$ The importance of this observation truly cannot be overstated, and the position in science and society granted to Dr. Watson was understandably profound. To this latter point, a memoir published describing his own role in this discovery, the Double Helix ${ }^{3}$ was ranked number 7 on the 100 best nonfiction books of the 20th century. ${ }^{4}$ On this background, one has to wonder why this (beyond) eminent scientist would disgrace himself with these comments. Were these comments truly the consequence of his (flawed but) careful consideration and scientific insight or were they the product of intellectual impairment brought on by some undisclosed medical illness. We must recall that the racist rants began when Dr. Watson was approaching the age of 80 (At this time he is 90).

Switching our focus from Dr. Watson, one must also wonder why we, as a society, are so obsessed with the concept of potential. We see this not only with intelligence but also with physical talents. The NFL combine draws more attention than some NFL games, never mind that arguably the game's 
greatest player, Tom Brady, had an absolutely dismal performance at this event. In contrast to physical skills in which how fast, strong and agile an athlete is SHOULD have SOMETHING to do with their eventual performance (again, never mind Mr. Brady), intellectual ability is a MUCH more difficult, perhaps impossible, parameter to measure with available tests. Despite the flaws in the assessment tools, our reliance on tests such as IQ, SAT, LSAT, and for our medical school MCAT, seems to be increasing in spite of our increasing understanding of their limitations; ethnic bias with standardized tests has been extensively documented and reviewed. ${ }^{5}$ This paradox continues to baffle me. In a 2015 manuscript, the Marshall medical education group reported that all the preadmission variable together could predict $<12 \%$ of the variance in eventual MLE performance. The MCAT exam alone was only good enough for half of this. Perhaps less surprising, the performance of students on actual medical school exams was a much better predictor of the ultimate MLE performance. Even the first exam in medical school alone was a better predictor than the preadmission variables. ${ }^{6}$ Given that the MCAT is a poor predictor of MLE performance and MLE performance yields, and at best only a partial assessment of a physician's abilities, you would think the MCAT would be devalued. Although some medical schools have dropped the requirement ${ }^{7}$, there is blind faith on the part of most schools that the new format of the MCAT will provide information lacking in previous versions. We do not have enough experience with this new format to say much about MLE performance, but I am personally dubious that we will find it to be much more effective than the earlier format.

People from different ethnic groups perform differently on the various aforementioned standardized tests. Concern has been raised that these tests are inherently biased to the ethnic and socioeconomic groups which are over-represented amongst the test designers. ${ }^{5}$ This is at the root of the "Watson" problem. Clearly Professor Watson feels that differences amongst races represented "real" differences in intelligence rather than this bias. At the level of medical school admissions, we glibly refer to performance on these standardized tests as part of an applicant's "credentials." Many people believe (with very little data to support this belief) that those with higher MCAT scores have greater potential as physicians and hence, "deserve" priority for admission. Lowering or eliminating minimum MCAT scores is seen as "lower standards" for the medical school. This belief is not provincial; it appears to be fairly widespread. In fact, US News and World Report uses the average matriculating MCAT score as a(n) (important) factor in their ranking of medical schools. Sadly, I think that the use of these standardized tests at so many critical areas of career progression (e.g., college admission, law and medical school admission, residency selection, etc.) perpetuates unconscious racism throughout our society. While our medical school is just a small part of the society we belong to, my hope is that we will have the courage to question these assumptions a bit going forward.

\section{AUTHOR AFFILIATIONS}

1. Marshall University Joan C. Edwards School of Medicine, Huntington, West Virginia

\section{REFERENCES}

1. Lab revokes honorary titles for Nobel Prize winner James Watson after repeated racist comments. 2019.

2. Watson JD, Crick FH. Molecular structure of nucleic acids: a structure for deoxyribose nucleic acid. J.D. Watson and F.H.C. Crick. Published inNature, number 4356 April 25, 1953. Nature. 1974;248:765.

3. Watson JD. The Double Helix. New York, New York: Atheneum; 1968.

4. 100 Best Nonfiction. 1998. at www. modernlibrary.com/top-100/100-bestnonfiction/.)

5. Minority testing bias persists. 2017. at https:// www.huffingtonpost.com/ronnie-reese/testbias-minorities_b_2734149.html.)

6. Gullo CA, McCarthy MJ, Shapiro JI, Miller BL. Predicting Medical Student Success on Licensure Exams. MedSciEdu 2015.

7. Average GPA and MCAT Score for Every Medical School (Updated in 2018). 2018. at https://www. shemmassianconsulting.com/blog/average-gpaand-mcat-score-for-every-medical-school.) 